\title{
Isolamento do vírus Parainfluenza bovino tipo 3 no Rio Grande do Sul, Brasil
}

\author{
Isolation of bovine Parainfluenza virus type 3 in Rio Grande do Sul, Brazil \\ Diocela Andrade Gonçalves ${ }^{1,2}$ Fernando Rosado Spilki ${ }^{1,2}$ Cláudio Chiminazzo ${ }^{2}$ \\ Michelle Andrade Oliveira $^{3}$ Ana Cláudia Franco ${ }^{1,2}$ Paulo Michel Roehe ${ }^{1,2,4}$
}

\section{RESUMO}

É descrito o isolamento do vírus Parainfluenza bovino tipo 3 (bPI-3) a partir de secreções nasais coletadas de um bovino com infecção respiratória. A identificação do agente foi realizada através de isolamento em cultivo celular e confirmada por testes de hemaglutinação, inibição da hemaglutinação, hemadsorção e imunofluorescência direta. Este é o primeiro registro do isolamento do vírus no Rio Grande do Sul.

Palavras-chave: parainfluenza bovina, bPI-3.

\section{ABSTRACT}

The isolation of bovine parainfluenza virus type 3 (bPI-3) from a case of mild respiratory disease in a calf is described. Identification was carried out by virus isolation in cell cultures and confirmed by hemagglutination, hemagglutination inhibition, hemadsorbtion and direct imunofluorescence. This is the first report on the isolation of bPI-3 in Rio Grande do Sul, Brazil.

Key words: bovine parainfluenza 3, bPI-3.

O vírus Parainfluenza bovino tipo 3 (bPI3) é membro da família Paramyxoviridae, gênero Paramyxovirus (MURPHY et al., 1999). O bPI-3 causa infecções respiratórias em bovinos e ovinos. $\mathrm{O}$ vírus foi isolado pela primeira vez, nos EUA, de secreção nasal de bovinos com sinais clínicos do quadro denominado "febre do transporte" (ANDREWES et al., 1955). Alguns anos mais tarde, o vírus foi isolado de terneiros que haviam participado de feiras (REISINGER et al., 1959). Alguns desses animais apresentavam dispnéia, tosse, descarga nasal serosa ou mucopurulenta, lacrimejamentto, conjuntivite, inapetência e temperatura elevada, sinais típicos da febre do transporte. Em terneiros infectados experimentalmente, a doença é caracterizada por febre, lacrimejamento, descarga nasal serosa abundante, depressão, dispnéia e tosse. Muitos animais exibem sinais clínicos brandos, recuperandose em poucos dias. Entretanto, a infecção pode resultar em pneumonia intersticial, afetando geralmente os lobos pulmonares anteriores (KAPIL et al., 1997).

No Brasil, a ocorrência da infecção, identificada através da detecção de anticorpos inibidores da hemaglutinação foi inicialmente realizada por CANDEIAS \& RIBEIRO (1968), que utilizaram uma cepa viral de origem humana, sendo mais tarde complementada por um estudo com a

${ }^{1}$ Médico Veterinário, Mestrando do Programa de Pós-graduação em Ciências Veterinárias, Faculdade de Veterinária, Universidade Federal do Rio Grande do Sul (UFRGS).

${ }^{2}$ Médico Veterinário, FEPAGRO Saúde Animal, Centro de Pesquisa Veterinária Desidério Finamor (CPVDF), Estrada do Conde 6000, 92990-000, Eldorado do Sul-RS, Brasil.

${ }^{3}$ Bolsista de Apoio Técnico (CNPq), CPVDF.

${ }^{4}$ Médico Veterinário, MSc, PhD., Professor Adjunto, Laboratório de Virologia, Instituto de Ciências Básicas da Saúde, UFRGS, \& CPVDF. CP 2076, 90001-970 Porto Alegre-RS, Brasil. E-mail: proehe@ufrgs.br. Autor para correspondência. 
amostra SF-4, de origem bovina. Neste último, foram detectadas $84,1 \%$ de positivos em 902 amostras de soro provenientes de criatórios no Estado de São Paulo (CANDEIAS \& RIBEIRO, 1970). No Rio Grande do Sul, WIZIGMANN et al. (1972) constataram $97 \%$ de reagentes positivos em 221 amostras de soro bovino. DAL PIZZOL et al. (1989) detectaram $70 \%$ de amostras positivas dentre 393 examinadas e $34 \%$ de positivas em 205 amostras de soro ovino testadas.

Apesar das evidências sorológicas da presença do vírus em nosso País, raramente tem sido reportado o isolamento do agente (CANDEIAS et al., 1971). No presente trabalho, são descritos o isolamento e a identificação do bPI-3 a partir de um caso de infecção respiratória leve em um terneiro, no Rio Grande do Sul.

Um bovino do plantel de reposição do laboratório, fêmea, de 1 mês de idade, apresentou apatia, febre, taquipnéia, corrimento nasal seroso abundante e lacrimejamento. Os sinais clínicos de comprometimento respiratório prolongaram-se por aproximadamente 7 dias, sendo ainda observados perda moderada de condição corporal e déficit na resistência ao exercício. Com o objetivo de evitar infecções secundárias, foram aplicadas três doses de oxitetraciclina (Terramicina LA, Pfizer), com intervalo de 5 dias, na dose e via recomendados pelo fabricante. Decorridos cerca de sete dias, o animal se recuperou da fase aguda da doença, sem seqüelas aparentes.

Para o isolamento viral, secreções nasais foram coletadas com suabes estéreis, os quais foram imediatamente imersos em $2 \mathrm{ml}$ de meio mínimo essencial de Eagle (MEM) adicionado de 500mg de enrofloxacina (Baytril - Bayer). Os suabes imersos em MEM foram mantidos à temperatura ambiente por 1 hora. Os frascos contendo os suabes foram submetidos à agitação mecânica por um minuto e os sobrenadante divididos e armazenados $\mathrm{a}-70^{\circ} \mathrm{C}$. Para o isolamento viral propriamente dito, alíquotas de sobrenadante foram descongeladas e filtradas em filtro $0,22 \mu \mathrm{m}$. A suspensão foi então inoculada em células MDBK, em monocamadas com $24 \mathrm{~h}$ de cultivo apresentando $90 \%$ de confluência, cultivadas em MEM suplementado com 50mg de enrofloxacina (Baytril) por litro de meio. As células inoculadas foram mantidas a $37^{\circ} \mathrm{C}$ para observação do efeito citopatogênico (ECP), juntamente com cultivos controle, não inoculados. Após 72h, o sobrenadante foi coletado, clarificado por centrifugação a $1000 \mathrm{rpm}$ por $10 \mathrm{~min}$ e filtrado. Após, foi feita uma segunda passagem do vírus em células MDBK e o mesmo titulado seguindo métodos usuais (CARBREY et al., 1971).
$\mathrm{O}$ isolado foi submetido à prova de hemaglutinação (HA) com hemácias de cobaio, conforme descrito por CARBREY et al. (1971). Em amostras de soro coletadas no início do quadro agudo (isto é, no dia em que foram identificados os primeiros sinais clínicos) e 28 dias após a recuperação do animal, foi realizado o teste de inibição da hemaglutinação (HI) frente à amostra padrão SF-4 (CARBREY et al., 1971). Paralelamente, foi utilizado um soro específico anti-bPI-3 (gentilmente cedido pelo Dr. F. Rijsewijk, ID-Lelystad, Holanda) como controle positivo.

Para o teste de hemadsorção, células MBDK infectadas com a amostra viral foram submetidas ao teste de hemadsorção com hemácias de cobaio a $0,4 \%$, por 30 minutos à temperatura ambiente, como descrito previamente (CHANOCK \& JOHNSON, 1989).

Para a imunofluorescência direta (IFD), em uma placa de microtécnica foram inoculadas 100 doses infectantes para $50 \%$ dos cultivos celulares por $50 \mu \mathrm{L}$ $\left(\mathrm{DICC}_{50}\right)$ do isolado. Após 96 horas, o meio sobrenadante foi desprezado e os cultivos fixados com $10 \mu \mathrm{L} /$ cavidade de uma solução de metanol e acetona (1:1). Passados 10 minutos, a placa foi secada e submetida à IFD utilizando conjugados específicos contra bPI-3, herpesvírus bovino tipo 1 (BHV-1), vírus da diarréia viral bovina (BVDV) e vírus respiratório sincicial bovino (BRSV), em diluição previamente determinada, em PBS ( $\mathrm{pH} 8,5)$, seguindo a metodologia recomendada pelo fabricante (Central Veterinary Agency, Weybridge, UK). Após a adição do conjugado, as placas foram levadas à câmara úmida por 30 minutos. Passado este período, o conjugado foi desprezado e foram realizadas três lavagens com PBS. A seguir, as placas foram lavadas com água destilada e adicionados $25 \mathrm{ul}$ de glicerina tamponada com PBS ( $\mathrm{pH} \mathrm{8,5).} \mathrm{As} \mathrm{placas} \mathrm{foram} \mathrm{submetidas} \mathrm{à}$ leitura em microscópio de fluorescência (Axiolab, Carl Zeiss). Foram incluídos controles positivos e negativos para todos os conjugados utilizados. Como controle de bPI-3 foi utilizada a amostra SF-4 (CARBREY et al., 1971).

Os soros coletados durante a fase aguda e 28 dias após foram submetidos à soroneutralização (SN) frente a bPI-3, BHV-1 e BVDV. A SN foi realizada essencialmente como descrita (HOUSE \& BAKER, 1971), com algumas modificações, como segue: em placas de 96 cavidades foram colocados $50 \mu \mathrm{L}$ de soro a ser testado em diluições seriadas $(1 / 2$ a 1/128). A seguir, foram adicionados $50 \mu \mathrm{L}$ de MEM contendo $100 \mathrm{DICC}_{50}$ das respectivas amostras de vírus (amostra SF-4 de bPI-3; amostra Cooper de 
BHV-1; amostra Singer de BVDV). Os testes foram realizados em placas distintas para cada vírus. As misturas soro/vírus foram incubadas a $37^{\circ} \mathrm{C}$ durante uma hora. A seguir, a cada poço das placas foram adicionados $50 \mu \mathrm{L}$ de suspensão de células MDBK a uma concentração de 1,5 a $3 \times 10^{4}$ células/orifício. Estas misturas foram então incubadas a $37^{\circ} \mathrm{C} \mathrm{em}$ atmosfera contendo $5 \%$ de $\mathrm{CO}_{2}$. As leituras das placas foram realizadas diariamente cinco dias após o início do teste. Os títulos foram calculados com base na identificação do ECP característico, sendo os cálculos efetuados pelo método de Reed e Müench (LORENZ \& BÖGEL, 1973).

Amostras de soro coletadas durante a fase aguda, aos 28 e 60 dias após a infecção foram ainda testados em um ensaio imunoenzimático (ELISA) indireto, específico para anticorpos anti bPI-3, como descrito previamente (GONÇALVES, 2002).

$\mathrm{Na}$ segunda passagem, $72 \mathrm{~h}$ após a inoculação da amostra, foi evidenciado ECP caracterizado pela presença de sincícios, arredondamento e morte celular. A quantificação do vírus revelou um título de $10^{4,8} \mathrm{DICC}_{50} / \mathrm{mL}$. A prova de hemadsorção com hemácias de cobaio igualmente teve resultado positivo em células MDBK infectadas. A IFD com conjugado anti-bPI-3 foi positiva. As reações para BHV-1, BRSV e BVDV foram negativas.

$O$ teste de HA da segunda passagem do isolado em células apresentou um título de 64. O título sérico de anticorpos inibidores da hemaglutinação frente ao bPI-3 na amostra de soro coletada durante a fase aguda foi 4 , ao passo que na amostra coletada 28 dias após, o título obtido foi 640. Não foi constatada a presença de anticorpos neutralizantes para os vírus BHV-1 e BVDV no soro, através do teste de soroneutralização. Não foi obtido resultado à SN frente ao bPI-3, em vista da ocorrência de efeito tóxico sobre os cultivos celulares, após várias repetições da prova. Entretanto, ao teste de ELISA, o nível de anticorpos anti-bPI-3 foi $<5$ na amostra coletada durante a fase aguda e 200 na amostra coletada aos 28 dias.

O primeiro isolamento do bPI-3, no Brasil, foi realizado por CANDEIAS et al., (1971), em São Paulo, quando foram identificadas quatro amostras de bPI-3, a partir de 25 amostras de pulmão bovino. Após esse estudo, pelo que se sabe, não mais foram publicados relatos de isolamento deste vírus no Brasil. $\mathrm{O}$ isolamento aqui reportado confirma a presença do vírus no Rio Grande do Sul, apesar de sua presença já haver sido há muito evidenciada através de estudos sorológicos (DAL PIZZOL et al., 1989; WIZIGMANN et al., 1972).
Os testes realizados confirmaram inequivocamente a identidade do agente.

Em países do hemisfério norte, a importância do bPI-3 está associada ao quadro clínico conhecido como "shipping fever", ou febre do transporte, na qual o animal desenvolve sinais clínicos após o transporte por longas distâncias, usualmente com grandes variações de temperatura, podendo o bPI-3 estar associado ou não a outros agentes, como Mannheimia hemolytica, Pasteurella multocida, Herpesvírus Bovino tipo 1, Adenovírus Bovino tipo 3 ou vírus Respiratório Sincicial Bovino (KAPIL \& BASARABA 1997). No Brasil, a importância do bPI3 é questionável, provavelmente devido às características climáticas bastante diferentes daquelas encontradas no hemisfério norte, não tendo sido sendo relatados até o presente (que sejam do conhecimento dos autores) casos de "febre do transporte". Na verdade, raras são as ocasiões em que os laboratórios de diagnóstico são solicitados a realizar testes de isolamento viral em casos de infecções respiratórias leves em bovinos.

Assim, em nosso meio, apesar da ampla distribuição do vírus, pouca atenção tem sido dada ao bPI-3 como agente patogênico na espécie bovina. Um detalhe que deve ser chamado à atenção é que as condições de manejo dos rebanhos brasileiros são bastante distintas daquelas encontradas em países do hemisfério norte. Além disso, a enfermidade causada pelo vírus, usualmente leve ou inaparente, provavelmente leva a que mais atenção seja dirigida a problemas sanitários de maior gravidade. No caso aqui relatado, como o animal encontrava-se sob constante vigilância, foi possível acompanhar o quadro clínico e proceder ao isolamento do vírus. Os sinais leves observados muito provavelmente passariam desapercebidos, em particular em rebanhos destinados a corte, nos quais dificilmente a infecção seria notada.

Curiosamente, parece haver um esforço significativo de alguns laboratórios para colocar no mercado vacinas multivalentes contendo antígenos de bPI-3. Permanece, portanto, a necessidade de avaliar o papel de infecções pelo bPI-3 na pecuária bovina em nosso meio, para que se possa recomendar com clareza medidas de prevenção e controle adequadas.

\section{AGRADECIMENTOS}

A amostra SF-4 de bPI-3 foi gentilmente cedida pela Dra. Sílvia Sardi. Trabalho realizado como parte da dissertação de mestrado de D.A.Gonçalves, a qual é bolsista do Programa de Pós-graduação em Ciências Veterinárias da Faculdade de Veterinária da UFRGS (PPG-CIVET/UFRGS). FRS é bolsista de mestrado do CNPq junto ao PPG-CIVET/UFRGS. ACF ébolsista 
recém doutor da FAPERGS. PMR é bolsista pesquisador do CNPq. Apoio PRONEX, CNPq \& FAPERGS.

\section{REFERÊNCIAS BIBLIOGRÁFICAS}

ANDREWES, C.H.; BANG, F.B.; BURNET, F.M. A short description of the Myxovirus Group (Influenza and Related Viruses). Virology, v.1, n.1, p.176-184, 1955.

CARBREY, E.A. et al. Recommended standard laboratory techniques for diagnosing infectious bovine rhinotracheitis, bovine diarrhea virus and shipping fever (Parainfluenza 3). Proceedings of the United States Animal Health Association, v.75, p.629648., 1971.

CANDEIAS, J.A.N.; RIBEIRO, L.C. Anticorpos inibidores da hemaglutinação para o vírus parainfluenza 3 (HA-1), em gado bovino. Revista de Saúde Pública, São Paulo, v.2, p.180-185, 1968.

CANDEIAS, J.A.N.; RIBEIRO, L.C. Anticorpos inibidores da hemaglutinação para as cepas SF-4 e HA-1 de Myxovirus parainfluenza 3, em gado bovino do estado de São Paulo. Arquivos do Instituto Biológico, v.37, p.129-35, 1970.

CANDEIAS J.A.N.; SUGAY,W.; RIBEIRO, L.C. Isolamento do Myxovirus parainfluenza $3 \mathrm{em}$ gado bovino do estado de São Paulo. Revista de Saúde Pública, v.5, p.207-212, 1971.

CHANOCK, R.M.; JOHNSON, M.D. Parainfluenza viruses. In: SCHMIDT, N.J.; EMMONS, R.W. Diagnostic procedures for viral and rickettsial diseases. 6.ed. New York : American Public Health Association Publications, 1989. p.470-486.

DAL PIZZOL, M. et al. Detecção de anticorpos para o vírus parainfluenza-3 em bovinos e ovinos no Rio Grande do Sul, Brasil,
1986. Arquivos da Faculdade de Veterinária UFRGS, Porto Alegre, v.17, p.59-64, 1989.

GONÇALVES, D.A. Desenvolvimento de métodos para a deteç̧ão de anticorpos contra da vírus parainfluenza bovinotipo 3. 1002. $55 \mathrm{f}$. Dissertação (Mestrado em Ciência Veterinária) - Curso de Pós-graduação em Ciências Veterinárias, Universidade Federal do Rio Grande do Sul.

HOUSE, J.A.; BAKER J.A. Bovine herpesvirus IBR-IPV. The antibody virus neutralization reaction. Cornell Veterinarian, v.61, p.320-335, 1971.

KAPIL, S.; BASARABA, R.J. Infectious bovine rhinotracheitis, parainfluenza-3, and respiratory coronavirus. Veterinary Clinics of North America, Bovine Practice, v.13, p.455-469, 1997.

LORENZ, R.J.; BÖGEL, K. Methods of calculation. In: KAPLAN, M.M.; KOPROWSKY, H. (Eds). Laboratory techniques in rabies. Geneva : World Health Organization, 1973. App.I, p.321-335.

MURPHY, F.A. et al. Paramyxoviridae. In: Veterinary virology. 3.ed. San Diego : Academic, 1999. p.411-428.

REISINGER, R.C.; HEDDLESTON, K.L.; MANTHEI, C.A.A. Myxovirus (SF-4) associated with shipping fever of cattle. Journal of the American Veterinary Medical Association, v.135, p.147-152, 1959.

WIZIGMANN, G.; VIDOR T.; RICCI, Z.M.T. Investigações Sorológicas sobre a ocorrência e incidência dos vírus da diarréia a vírus-enfermidade das mucosas dos bovinos, no estado do Rio Grande do Sul. Boletim do Instituto de Pesquisas Veterinárias "Desidério Finamor", v.1, p.5258, 1972. 